\title{
Expander Selection for an on board ORC energy recovery system
}

\author{
Fabio Pantano', Roberto Capata ${ }^{2}$ \\ ${ }^{1}$ Department of Mechanical and Aerospace Engineering, University of Rome "Sapienza", Via Eudossiana, 18, 00184, Rome, \\ Italy; corresponding author. \\ E-mail: fabio.pantano.92@gmail.com \\ ${ }^{2}$ Department of Mechanical and Aerospace Engineering, University of Rome "Sapienza", Via Eudossiana, 18, 00184, Rome, \\ Italy; \\ E-mail: roberto.capata@uniroma1.it
}

\begin{abstract}
This paper deals with the comparison between volumetric expanders (screw, scroll and rotary vane) and an Inlet Forward Radial (IFR) micro turbine for the exploitation of an on board Organic Rankine Cycle (ORC) energy recovery system. The sensible heat recovered from a common bus engine (typically $8000 \mathrm{cc}$ ) feeds the energy recovery system that can generate sufficient extra power to sustain the air-conditioning system and part of the auxiliaries. The concept is suitable for all kind of thermally propelled vehicles, but the application considered here is specific for an urban bus. The ORC cycle performance is calculated by a Process Simulator (CAMEL Pro) and the results are discussed. A preliminary design of the considered expanders is proposed using ad-hoc made models implemented in MATLAB; the technical constraints inherent to each machine are listed in order to perform the optimal choice of the expander based on efficiency, reliability and power density. Last step will be the selection of the expander that suites the specific technical and design requests. The final choice relapsed on the screw motor, for it is the best compromise in terms of efficiency, lubrication and reliability.
\end{abstract}

\section{Keywords}

Organic Rankine Cycle, Energy Recovery Systems, Micro turbine, Screw expander, Rotary Vane expander, Scroll expander

\section{Highlights}

- Determination of the cycle parameters for the on board ORC energy recovery system.

- Design of an IFR micro-turbine expander based on Rohlik method.

- Design of a Screw Expander, a Rotary Vane Expander and a Scroll Expander.

Comparison of the expanders and final choice.

\section{Nomenclature}

$\begin{array}{llll}\dot{m} & \text { mass flow rate }[\mathrm{kg} / \mathrm{s}] & \phi & \text { flow coefficient } \\ T & \text { temperature }[\mathrm{K}] & \alpha & \text { real velocity angle }\left[{ }^{\circ}\right] \\ p & \text { pressure }[\mathrm{Pa}] & \beta & \text { relative velocity angle }\left[{ }^{\circ}\right] \\ D & \text { diameter }[\mathrm{m}] & z & \text { number of blades } \\ \delta & \text { blockage factor } & \eta & \text { efficiency } \\ V & \text { real flow velocity }[\mathrm{m} / \mathrm{s}] & h & \text { enthalpy }[\mathrm{J} / \mathrm{kg}] \text { or height }[\mathrm{m}] \\ W & \text { relative flow velocity }[\mathrm{m} / \mathrm{s}] & n_{S} & \text { adimensional specific speed } \\ U & \text { blade velocity }[\mathrm{m} / \mathrm{s}] & d_{s} & \text { adimensional diameter } \\ \rho & \text { density }\left[\mathrm{kg} / \mathrm{m}^{3}\right] & R_{\rho} & \text { degree of reaction } \\ \psi & \text { head coefficient }[\mathrm{m}] & P & \text { power }[\mathrm{W}]\end{array}$




$\begin{array}{ll}V & \text { volume or displacement }\left[\mathrm{m}^{3}\right] \\ Q & \text { volumetric flow rate }\left[\mathrm{m}^{3} / \mathrm{s}\right] \\ r_{p} & \text { pressure ratio } \\ r_{V} & \text { volume ratio } \\ \theta & \text { angle }\left[{ }^{\circ}\right] \\ R & \text { radius }[\mathrm{m}] \\ e & \text { eccentricity }[\mathrm{m}]\end{array}$

\section{Subscripts}

$0 \quad$ IFR turbine stator inlet

$1 \quad$ IFR turbine rotor inlet

2 IFR turbine rotor outlet

eul eulerian

ex exhausted gas

\section{Abbreviations}

$\begin{array}{ll}r_{R} & \text { rotor radius [m] } \\ \mu & \text { viscosity [Pl] } \\ \phi_{e} & \text { ending angle of involutes }\left[{ }^{\circ}\right] \\ \tau & \text { orbiting angle of moving scroll around } \\ & \begin{array}{l}\text { the fixed scroll }\left[{ }^{\circ}\right] \\ \text { partial load efficiency }\end{array}\end{array}$

in inlet

leak leakages

mid midspan

out outlet

$\begin{array}{llll}\text { IFR } & \text { Inward Flow Radial } & \text { EM } & \text { Electric Motor } \\ \text { ORC } & \text { Organic Rankine Cicle } & M T B F & \text { Mean Time Between Failure } \\ H R S G & \text { Heat Recovery Steam Generator } & P L E & \text { Partial Load Efficiency } \\ I C E & \text { Internal Combustion Engine } & & \end{array}$

\section{Introduction}

The Communication from the commission to the European Parliament and the Council concerning the European new energy politics in 2014 [1] reports on the outlook for attainment of the $20 \%$ target for energy efficiency in 2020, and up to $30 \%$ in 2030. Of course energy efficiency has a primary role in this transition to a more sustainable and competitive Europe. However, in order to accomplish this project, future growth must be driven according to a different mentality: less primal energy consumption and at lower costs. Considering the Evolution of Energy consumption in Europe from 1995, it can be noticed how well before the crisis hit in 2008, the EU had started to decouple economic growth from energy consumption through increased energy efficiency, and this attitude has continued since then. The best way to reduce primary energy consumption is not wasting it $[2,3]$. It should be considered that because of the thermodynamics laws every machine that produces power also produces waste heat by need, which, in real machines, can be reduced. In this sense regenerative cycles, cogeneration, tri-generation, thermal storage and pre-heating $[4,5,6,7]$ are well known technologies that are applied in almost every power plant, and the recovery of waste heat is one of the most explored engineering field in the last decade. So, adding a bottoming Organic Rankine Cycle waste heat recovery process to industrial power plants is not at all a new idea, although these power plants have seen limited production due to the high cost of engineering and construction related to the physiologic low power output. Nevertheless, due to the modern increasing and not stable primary energy cost which results from the delicate Middle East politics, in the last years ORC power plants have seen an important growth [8]. Most of the ORC bottoming cycles are used for heavy-duty stationary power plants or for geothermal and biomass power plants, but the relatively new idea of using this technology to recover waste heat from Diesel internal combustion engines for on-road applications is becoming more appealing. Of course, in Diesel ICE exhausted gasses are already used in the supercharger to increase the cylinder filling factor, but after the turbine, especially in heavy-duty trucks or busses, exhausted gasses still have an interesting enthalpy that is possible to recover. In this paper, the feasibility on an on-board ORC recovery system for heavy-duty automotive applications is explored. In particular, the main purpose of this work is comparing different types of expanders, from micro turbines to volumetric machines, in order to determinate the optimal type of expander for each target application. 


\section{Problem Setting}

\subsection{Initial Data}

The target ORC cycle operates as a bottoming cycle of a common Diesel 8000cc engine for bus applications. The in-cruise condition of the exhausted gasses, after the supercharger turbine, are the ones expressed in Table 1 .

Table 1: In-cruise condition of the exhausted gasses.

\begin{tabular}{ccc}
\hline$\dot{m}_{\text {exhausted }}[\mathrm{kg} / \mathrm{s}]$ & $T_{\text {exhausted }}[\mathrm{K}]$ & $p_{\text {exhausted }}[$ bar $]$ \\
0.8 & 800 & $\approx 1$
\end{tabular}

The organic fluid R245fa was chosen for it is one of the most used organic fluids for its reliability and its favorable performance in heat recovery systems. In fact, considering a homologous series of chemical species, as chain length and molecular weight increase, the molar heat capacity and entropy increase, as it will be explained in a short. More specifically, with comparable latent heats, as the slope of the entropy lines decrease, the cycle efficiency will increase. In fact, given the proportionality between the natural logarithmic of pressure and the inverse of temperature, for small changes in temperature, the slope of the entropy line will be approximately the change in enthalpy with change in temperature that represents the heat capacity. Even though R11, R123 and R245fa are not in the same homologous series, the longer molecular chain length of R245fa means that the vibrational component of heat capacity will increase as well as the entropy due to the increased degrees of freedom. These characteristics make R245fa one of the most appealing fluids for ORC applications. [9] Regardless the fluid choice, since R245fa is an HFC with a GWP greater than 1000 and important fluids banning are expected in the next years, the expanders design programs, made with MATLAB, support every fluid in the CoolProp database.

\subsection{The cycle}

Steady-state simulations of the plant have been performed using the CAMEL-Pro process simulator in order to analyze the system performance and to choose the evolving mass flow rate with respect to a reasonable cooling mass flow rate into the condenser. The CAMEL -Pro (Calculation by Modular Elements) software has been developed at the Department of Mechanical and Aerospace Engineering of the University of Rome "la Sapienza". It is written in $\mathrm{C}++$, is based on an object-oriented approach and is equipped with a user friendly interface in which the system is represented as a network of components connected by energy or flow streams; each component is characterized by a set of equation which describe the thermodynamic evolution imposed on the streams. The complete solution is available after having assigned the right boundary conditions [10,11]. Even if recent studies suggest different cycle solutions [12,13], since our purpose is the comparison of different expander types, a simple circuit has been considered. (Figure1)

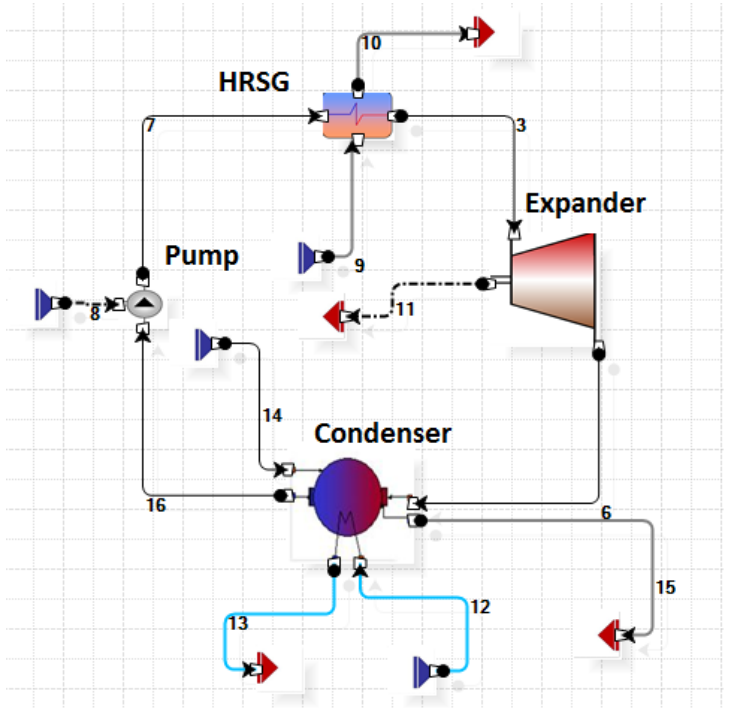


Figure 1: ORC cycle

Given the ICE working conditions, recalling Figure 2, after having chosen a pitch point temperature $\Delta T_{p p}=$ $20^{\circ} \mathrm{C}$, preliminarily considering a constant $c_{p}$, the maximum working fluid mass flow rate has been evaluated as:

$\dot{\mathrm{m}}_{\mathrm{R} 245 \mathrm{fa}, \max }=\frac{\dot{\mathrm{m}}_{\text {exhausted }} \mathrm{cp}^{\prime}\left(\mathrm{T}_{4}-\mathrm{T}_{\mathrm{M}}-\Delta \mathrm{T}_{\mathrm{pp}}\right)}{\mathrm{h}_{0}-\mathrm{h}_{\mathrm{M}}} \cong 1.5 \mathrm{~kg} / \mathrm{s}$

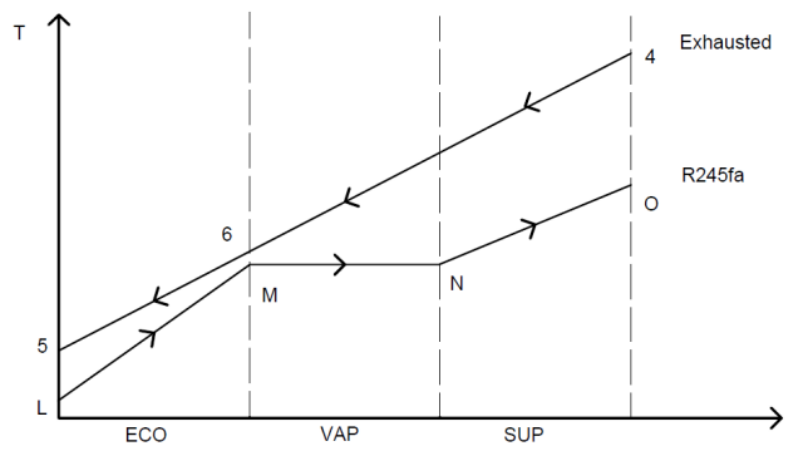

Figure 2: Ideal temperatures behavior in the HRSG

However, the chosen mass flow rate is much lower. In fact, as previously mentioned, one has to find a good balance between an high mass flow rate of the working fluid, which affects directly the power output, and a reasonable mass flow rate of the cooling water in the condenser Being the condenser a massive component, it should not, in any case, compromise the feasibility on an on-board system. The working fluid is compressed to a maximum pressure equal to $1 \mathrm{MPa}$. Successively, it is heated, boiled and reheated to $414 \mathrm{~K}$ within the HRSG. The aim is to reach an expansion pressure equal to $185 \mathrm{kPa}$ and, then, condenses it at $293 \mathrm{~K}$. All boundary conditions (temperatures, pressure, etc.) have been fixed on similarity with existing ORC devices (i.e. [14]), to obtain a sufficient enthalpy drop in the expander and maintain the working fluid quite far to the critical point. The final operative conditions are shown in Table2.

Table 2: Cycle working conditions

\begin{tabular}{|c|c|c|c|}
\hline Parameter & Value & Parameter & Value \\
\hline$\dot{m}_{e x}$ & $0.8 \mathrm{~kg} / \mathrm{s}$ & $\boldsymbol{T}_{\boldsymbol{R} \mathbf{2 4 5} \boldsymbol{f} \boldsymbol{a}}$ at expander outlet & $368 \mathrm{~K}$ \\
\hline $\boldsymbol{T}_{\boldsymbol{e x}}$ at HRSG inlet & $800 \mathrm{~K}$ & $p_{R 245 f a}$ at expander outlet & $180 \mathrm{kPa}$ \\
\hline $\boldsymbol{T}_{\boldsymbol{e x}}$ at HRSG outlet & $620.5 \mathrm{~K}$ & $\boldsymbol{T}_{\boldsymbol{R} 245 \mathrm{fa}}$ at condenser outlet & $293 \mathrm{~K}$ \\
\hline $\boldsymbol{p}_{\boldsymbol{e x}}$ at HRSG inlet & $101.3 \mathrm{kPa}$ & $\boldsymbol{p}_{\boldsymbol{R} \mathbf{2 4 5} \boldsymbol{f a}}$ at condenser outlet & $177 \mathrm{kPa}$ \\
\hline $\boldsymbol{p}_{\boldsymbol{e x}}$ at HRSG outlet & $99.3 \mathrm{kPa}$ & $\dot{\boldsymbol{m}}_{\text {water }}$ & $2.24 \mathrm{~kg} / \mathrm{s}$ \\
\hline$\dot{m}_{R 245 f a}$ & $0.5 \mathrm{~kg} / \mathrm{s}$ & $\boldsymbol{T}_{\boldsymbol{w a t e r}}$ at condenser inlet & $290 \mathrm{~K}$ \\
\hline $\boldsymbol{T}_{\boldsymbol{R} \mathbf{2 4 5} \boldsymbol{f a}}$ at HRSG inlet & $294 \mathrm{~K}$ & $\boldsymbol{p}_{\text {water }}$ at condenser inlet & $101.3 \mathrm{kPa}$ \\
\hline $\boldsymbol{T}_{\boldsymbol{R 2 4 5} \boldsymbol{f a}}$ at HRSG outlet & $413 \mathrm{~K}$ & $T_{\text {water }}$ at condenser outlet & $304 \mathrm{~K}$ \\
\hline $\boldsymbol{p}_{\boldsymbol{R} 245 \boldsymbol{f a}}$ at HRSG inlet & $1000 \mathrm{kPa}$ & $\boldsymbol{p}_{\boldsymbol{w a t e r}}$ at condenser outlet & $100 \mathrm{kPa}$ \\
\hline $\boldsymbol{p}_{\boldsymbol{R} 245 \boldsymbol{f} \boldsymbol{a}}$ at HRSG outlet & $980 \mathrm{kPa}$ & $P_{n e t}$ & $18 \mathrm{~kW}$ \\
\hline
\end{tabular}

\subsection{The expander problem}

Although in heavy-duty power plants turbines dominate the field of the expanders, the choice of the most convenient machinery for relatively small-scale recovery systems is not straightforward. In fact, on one hand, turbines offer high reliability, compactness and the highest specific power; but in the other hand, in micro-scale systems, their high rotational speed and their needs to operate in steady state conditions, limit their utilization. In fact, in these niche applications, the use of positive displacement expanders are generally preferred. Volumetric expanders, indeed, can operate smoothly in unsteady conditions, and their remarkable lower rotational speed allows a direct connection with a commercial electric generator, with no gearbox. The gearbox is an extra cost, huge for high reduction ratios and has to be rebuilt every 3-5 years. Lower rotational speed also allows the use of slower speed shaft bearings, which increases the longevity of the machine operation, and less frequent maintenance intervals. Nevertheless, volumetric expanders have lubrication issues, which must be dealt with. However, 
these issues can be partially solved with the correct choice of working fluid. In fact some organic fluids have interesting lubricant proprieties, that reduce and, in some particular cases such as the "dry screws", dismisses the use of lubricant oil. Notwithstanding the advantages of choosing a positive displacement expander, it is important to enlighten that no volumetric machinery could challenge a turbine efficiency, compactness and power-to-weight ratio. In this work, for the fixed thermodynamic cycle, a preliminary design of a micro turbine, a screw expander, a rotary vane expander and a scroll expander is proposed. Results are then discussed and compared, to propose a general procedure in choosing the expander, with the optimal compromise between expected efficiency, compactness, lubrication issues, EM coupling, operative ranges, realization cost and commercial availability.

\section{IFR Micro turbine}

\subsection{Design: Parameters choice}

The design of a classical IFR (Inward-Flow Radial) Turbine has been performed based on the methods proposed in the past by Rohlik [16] and Balje [18]. Design is made with Matlab with the CoolProp add-in in order to evaluate the fluid proprieties. The code is implemented in order to generate the turbine geometry with the following procedure for every input fluid and input data. For the preliminary turbine design, Rohlik approach is proposed [16]. In his work, Rohlik has studied radial centripetal turbines performance in analytic way, to determine the optimal geometry for different applications, each one identified by characteristic parameter called "specific speed" $\left(\Omega_{\mathrm{s}}\right)$. This parameter depends on the complementary exit nozzle flow angle $\alpha_{1}^{c}$, diameter ratio between inlet and mid-span outlet section $\left(\mathrm{D}_{2 \mathrm{mid}} / \mathrm{D}_{1}\right)$, rotor inlet blade height to inlet diameter ratio $\left(\mathrm{b}_{1} / \mathrm{D}_{1}\right)$. So, the specific speed is defined as:

$\Omega s=(2)^{\frac{7}{2}} \cdot(\pi)^{\frac{1}{2}} \cdot\left(\frac{4 \cdot\left(\tan \alpha_{1}^{c}\right)^{2}}{\left(\frac{D_{2 m i d}}{D_{1}}\right)^{2}}-1\right)^{\frac{1}{4}} \cdot\left(\frac{b_{2}}{D_{2 m i d}}\right)^{\frac{1}{2}} \cdot\left(\frac{D_{2 m i d}}{D_{1}}\right)^{\frac{3}{2}} \cdot\left(\frac{U_{1}}{C_{s p}}\right)^{\frac{3}{2}}$

where $C_{s p}$ is the so-called "spouting velocity" $\mathrm{C}_{\mathrm{sp}}=\sqrt{2 \cdot\left(\mathrm{h}_{0}^{0}-\mathrm{h}_{2 \mathrm{~s}}^{0}\right)}$.

Figure 3 shows the trend of the turbine efficiency as a function of the specific speed, highlighting the dependence of the efficiency from the incidence angle $\alpha_{1}^{c}$.

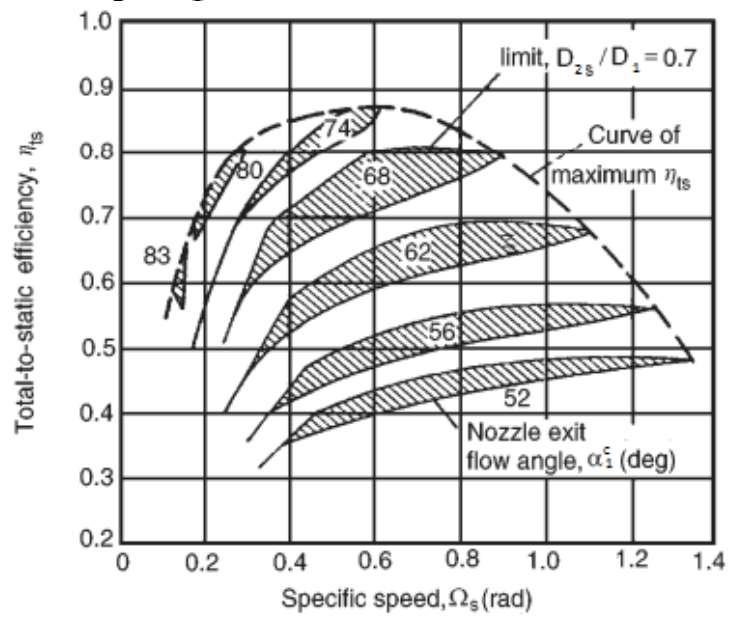

Figure 3: Trend of the turbine efficiency adapted from [14]

Table 3. shows the parameters that have been kept constant in the design of the IFR.

Table 3: Rohlik parameters

\begin{tabular}{cccc}
\hline Parameter & Value & Parameter & Value \\
\hline $\boldsymbol{\alpha}_{\mathbf{1 c}}$ & $74^{\circ}$ & $\boldsymbol{\alpha}_{\mathbf{1}}$ & $16^{\circ}$ \\
$\boldsymbol{D}_{\mathbf{2 h u b}} / \boldsymbol{D}_{\mathbf{2 s h r o u d}}$ & 0.4 & $\boldsymbol{D}_{\mathbf{2 s h r o u d}} / \boldsymbol{D}_{\mathbf{1}}$ & 0.7 \\
$\boldsymbol{D}_{\mathbf{2 m i d}} / \boldsymbol{D}_{\mathbf{1}}$ & 0.49 & $\boldsymbol{\psi}_{\mathbf{1}}$ & 1 \\
$\boldsymbol{\psi}_{\mathbf{2}}$ & 0 & $\boldsymbol{W}_{\mathbf{2 m i d}} / \boldsymbol{W}_{\mathbf{1}}$ & 2
\end{tabular}




\subsection{Design: Geometry}

The design of the IFR turbine is iterative, processed with Matlab and consistent with [17].

Table 4: Input data for the IFR microturbine design

\begin{tabular}{cccc}
\hline Parameter & Value & Parameter & Value \\
\hline $\boldsymbol{p}_{\mathbf{0}}$ & $1000 \mathrm{kPa}$ & $\boldsymbol{T}_{\mathbf{0}}$ & $413 \mathrm{~K}$ \\
$\dot{\boldsymbol{m}}$ & $0.5 \mathrm{~kg} / \mathrm{s}$ & $\boldsymbol{R}_{\boldsymbol{\rho}}$ & 0.5 \\
\hline
\end{tabular}

The quantities reported in the following paragraphs are the resulting ones from the last iteration. Given the input data in Table 4 the code starts assuming a preliminary efficiency: $\eta_{\text {guess }}$ and a degree of reaction $R_{\rho_{\text {guess }}}$.

$\eta=\eta_{\text {guess }} \quad R_{\rho}=R_{\rho_{\text {guess }}}$

The thermodynamic parameters at the end of the expansion with the given efficiency are evaluated via CoolProp software, and a preliminary design with Rohlik procedure is advanced. Known the enthalpy and the pressure, all the relevant thermodynamic parameters are then computed. Similarly, the post-nozzle parameters are evaluated from the $R_{\rho}$ assumption. In Table 5 the parameters at the last iteration are reported.

Table 5: Thermodynamic parameters at the last iteration

\begin{tabular}{cccc}
\hline Parameter & Value & Parameter & Value \\
\hline $\boldsymbol{T}_{\mathbf{1}}$ & $392.76 \mathrm{~K}$ & $\boldsymbol{p}_{\mathbf{1}}$ & $494.77 \mathrm{kPa}$ \\
$\boldsymbol{\rho}_{\mathbf{1}}$ & $21.72 \mathrm{~kg} / \mathrm{m}^{3}$ & $\boldsymbol{Q}_{\mathbf{1}}$ & $0.0230 \mathrm{~m} 3 / \mathrm{s}$ \\
$\boldsymbol{T}_{\mathbf{2}}$ & $372.53 \mathrm{~K}$ & $\boldsymbol{p}_{\mathbf{2}}$ & $180 \mathrm{kPa}$ \\
$\boldsymbol{\rho}_{\mathbf{2}}$ & $8.01 \mathrm{~kg} / \mathrm{m}^{3}$ & $\boldsymbol{Q}_{\mathbf{2}}$ & $0.0624 \mathrm{~m} 3 / \mathrm{s}$ \\
$\boldsymbol{h}_{\mathbf{0}}$ & $527.7 \mathrm{~kJ} / \mathrm{kg}$ & $\boldsymbol{h}_{\mathbf{1}}$ & $511.6 \mathrm{~kJ} / \mathrm{kg}$ \\
$\boldsymbol{h}_{\mathbf{2}_{\text {real }}}$ & $494.7 \mathrm{~kJ} / \mathrm{kg}$ & $\boldsymbol{W}_{\text {eul }}$ & $32.96 \mathrm{~kJ} / \mathrm{kg}$ \\
\hline
\end{tabular}

The actual design is then processed. The resulting rotor peripheral velocity is:

$$
\mathrm{U}_{1}=\sqrt{\frac{\mathrm{W}_{\mathrm{eul}}}{\psi_{1}}}
$$

a value for $n_{s}=0.5$ is fixed, and using the specific speed equation

$$
\mathrm{n}_{\mathrm{s}}=\frac{\omega \sqrt{\mathrm{Q}}}{\mathrm{L}_{\text {eul }}^{3 / 4}}
$$

the turbine rotational speed is computed equal to $\omega=4896.4 \mathrm{rad} / \mathrm{s}$. Resulting velocity was then corrected to $\omega=4712.4 \mathrm{rad} / \mathrm{s}$ in order to be a multiple of $2 \pi * 50$ which is the common rotational speed for a $50 \mathrm{~Hz}$ generator. The external diameter is then evaluated and set equal to $\mathrm{D}_{1}=\frac{2 \mathrm{U}_{1}}{\omega}=7.71 \mathrm{~cm}$.

Then, considering the parameters from Table 3 the velocity triangles are generated and reported in Table 6 .

Table 6: Velocity Triangles of the IFR microturbine

\begin{tabular}{cccc}
\hline & Value & Parameter & Value \\
\hline Parameter & & & $57.16 \mathrm{~m} / \mathrm{s}$ \\
$\boldsymbol{U}_{2 \text { mid }}$ & $88.96 \mathrm{~m} / \mathrm{s}$ & $\boldsymbol{U}_{2 \text { hub }}$ & $120.76 \mathrm{~m} / \mathrm{s}$ \\
$\boldsymbol{V}_{2 \text { mid }}$ & $45.86 \mathrm{~m} / \mathrm{s}$ & $\boldsymbol{U}_{2 \text { shroud }}$ & 0.802 \\
$\boldsymbol{W}_{2 \text { mid }}$ & $100.09 \mathrm{~m} / \mathrm{s}$ & $\boldsymbol{\phi}_{\text {2hub }}$ & 0.380 \\
$\boldsymbol{\beta}_{2 \text { mid }}$ & $27.27^{\circ}$ & $\boldsymbol{\phi}_{2 \text { shroud }}$ & $38.74^{\circ}$ \\
$\boldsymbol{\phi}_{\text {2mid }}$ & 0.516 & $\boldsymbol{\beta}_{\text {2hub }}$ & $20.80^{\circ}$ \\
\hline
\end{tabular}


For consistency with Rohlik method, one has to verify that:

$\frac{\mathrm{D}_{2 \text { hub }}}{\mathrm{D}_{2 \text { shroud }}}=0.47>0.4$ and $\frac{\mathrm{D}_{2 \text { shroud }}}{\mathrm{D}_{1}}=0.67<0.7$

Once the velocity triangles are determined, the actual value of $R_{\rho_{\text {actual }}}$ is evaluated:

$\mathrm{R}_{\rho \mathrm{mid}}=1-\frac{\psi_{1}+\Psi_{2}}{2}+\frac{\phi_{1}^{2}-\phi_{2 \mathrm{mid}}^{2}}{2 \cdot\left(\psi_{1}-\psi_{2}\right)}$

Then, an error between the actual value and the initial value is computed, the initial value is updated to the actual value, and the procedure is iterated from the determination of post-nozzle values until the error is minor than a given value.

\subsection{Efficiency}

To obtain indicative value of turbine efficiency, the specific speed $\Omega_{\mathrm{s}}$ is evaluated with equation proposed by Dixon [19]:

$\Omega_{\mathrm{s}}=2,11 \cdot\left(\mathrm{c}_{2} / c_{0}\right)^{\frac{1}{2}} \cdot\left(\mathrm{A}_{2} / A_{d}\right)^{\frac{1}{2}}=0.49$

Where $\mathrm{c}_{0}$ is the spouting velocity and:

$$
\mathrm{A}_{2}=\mathrm{Q}_{2} / \mathrm{V}_{2}=1.2610^{-3} \quad ; \quad \mathrm{A}_{\mathrm{d}}=\frac{\pi \cdot \mathrm{D}_{1}^{2}}{4}=4.1310^{-3}
$$

Figure 3 showing the expected efficiency has been digitized and imported in Matlab so that, once $\Omega_{s}$ and the value of $\alpha_{1}{ }^{c}$ are known, the program is able to determine the expected efficiency.

An error between the preliminary guessed efficiency and the Rohlik expected efficiency is computed. The guessed efficiency is updated to the Rohlik evaluated efficiency, and the procedure from (4) is iterated until the error is minor than a given value. Lastly, the program returns the velocity triangles, the geometry of the turbine, the final expected efficiency and the total expected power.

The final efficiency is:

$\eta_{\text {turbine }}=0.85$

And the expected total power output:

$\mathrm{P}_{\text {out }}=\eta_{\text {turbine }} \dot{\mathrm{m}} \Delta \mathrm{h}_{\text {is }}=16.48 \mathrm{~kW}$

Lastly, he number of the rotor blades is evaluated with the formula:

$\mathrm{Z}_{\text {rot }} \geq \frac{\pi}{30}\left(\alpha_{1}^{\circ}+20\right) \cot \alpha_{1}$

Where $\alpha_{1}^{\circ}$ is the angle in degrees and $\alpha_{1}$ is the angle in radians.

Table 7 summarizes the resulting design of the IFR.

Table 7. IFR design results

\begin{tabular}{cccc}
\hline Parameter & Value & Parameter & Value \\
\hline$D_{1}$ & $77.1 \mathrm{~mm}$ & $b_{1}$ & $2.24 \mathrm{~mm}$ \\
$D_{2 \text { mid }}$ & $37.8 \mathrm{~mm}$ & $b_{2}$ & $13.50 \mathrm{~mm}$ \\
$\omega$ & $4710 \mathrm{rad} / \mathrm{s}(45000 \mathrm{rpm})$ & $Z$ & 14 \\
$\eta$ & 0.85 & $P$ & $16.48 \mathrm{~kW}$ \\
\hline
\end{tabular}




\section{Screw expanders}

\subsection{Screw Overview}

Screw machines employed as motors, utilizing the expansion of vaporous working fluids, are available in decentralized energy systems in the low and medium rated power ranges. In these applications, the high efficiency and good performance under partial-load conditions, over a wide load range, are mainly responsible for the energy-based advantages of the screw motor compared with other mechanical concepts. Low requirements for the working fluid, make it possible, to use almost every vapor, even normal steam, in any non-critical form. The influence of the geometrical machine parameters on the thermodynamic operating ORC plants has been already examined and assessed, in quantitative terms. The geometry-dependent principal loss mechanism are the choke effects and gap losses, during the charging phase. At same time, some researchers have been demonstrated how an increased of operating pressure, without superheating, is advantageous both for the heat transmission at large scale, as well as, for a maximization of the net power output. [20,21] Moreover, the use of screw machines has been proven to be advantageous in those application, where the liquid inside the expansion machine is expected, because the condensate performs as a sealing at high tip speeds, decreasing leakage losses.

\subsection{Volumetric Efficiency}

To determine the volumetric efficiency, proceed as follows. At the entrance, due to the narrowing of the section, the front door behaves like a converging nozzle. Therefore, at the beginning of the expansion, the chamber pressure is lower than the inlet pressure. The presence of gaps generates a mass flow towards the output, varying the volumetric efficiency (Figure 4).

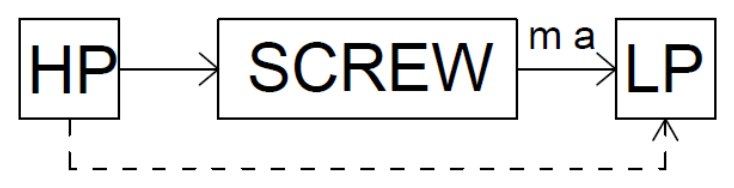

m leak

\section{Figure 4: Gap mass flow towards the outlet}

These gaps do not depend on the angle of rotation. In addition, they influence the filling procedure of the Chamber and the available space on the pressure side. Depending on the "weight" of these aspects, the yield varies from a minimum to a maximum. Therefore, since the yield is variable, it is much more reasonable to use the isentropic yield. This yield quantifies the energy made available by the fluid to the expander. It defines losses during the efflux of the fluid between inlet and outlet. Finally, isentropic efficiency decreased as the volumetric yield decreased, due to a reduction in the evolving flow rate $[20,21]$. For these reasons, the output power has to be maximized

\subsection{Lubrication issues}

To ensure lubrication, an oil circuit has to be considered (Figure 5).

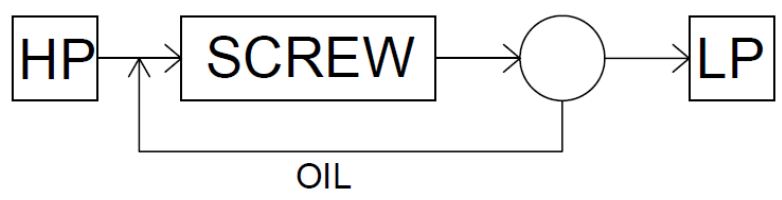

Figure 5: Oil circuit

Circumferential speed for "wet rotors" is about $20-40 \mathrm{~m} / \mathrm{s}$. Moreover, most of the screw motors/compressors are unsynchronized. In "unsynchronized" devices, only the male screw is moved by the motor. The others are moved by the contact between the screws.

In synchronised machines, the second screw is also moved by the engine. In this way, the screws do not touch and increase the losses. Therefore, the expander does not need lubrication, but a timing gear that prevents contact between the rotors. For reducing losses, the various "synchronized" devices are characterized by a high peripheral speed $(60-120 \mathrm{~m} / \mathrm{s})$. This aspect is fundamental in the preliminary machine desing. It is necessary to evaluate the need for a timing gear, and the increase in the flow of working liquid, in the operating chambers. It depends, 
substantially, on the lubrication properties of the fluid in the working chambers. In the case that the working fluid ensures adequate lubrication, the unsynchronized configuration is preferred. In this case, a lighter, smaller construction machine, with a simple, more reliable and energetically more efficient assembly are expected. The studies confirm that, during operation, a part of the working liquid operates as a sealant (for centrifugal effect). The design of a screw expander is, therefore, oriented towards the machine with direct fluid injection and in unsynchronized configuration, with rotor and bearings lubricated by the working fluid itself.

\subsection{Design model}

The most important feature in designing a twin-screw machine is the rotor profile. The earliest machines used a symmetric profile with the male rotor shape composed of circles whose centers are positioned either at the rotor center or on its pitch circle as shown in Figure 6, while the female rotor just reflects this configuration [18].

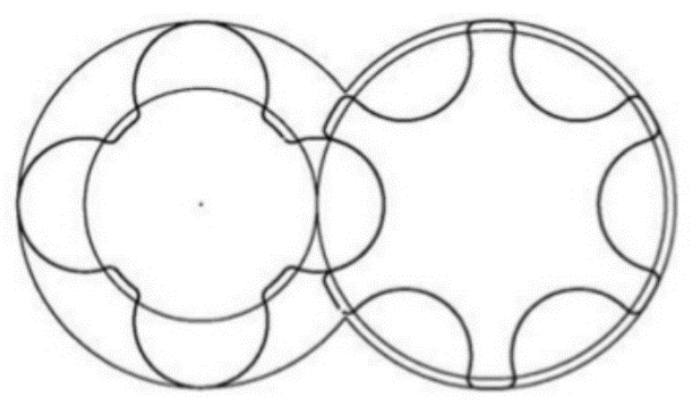

Figure 6: Symmetric profile

Since the introduction of the symmetrical and circular profile, many improved profiles have been developed and studied. The "N" profile, developed at the London City University, is now widely used by screw machinery manufacturers for its many advantages, including lower transmission torque (with a relative decrease of friction), strong female rotors, a dedicated large processing volume for the fluid, and a shorter seal between the rotors, which guarantees a losses reduction. Moreover, its application increases the adiabatic efficiency, especially at lower tip speeds, where benefits of almost $10 \%$ over other profiles have been recorded. The typical couple of "N" rotor profiles, as [22] is shown in Figure 7.
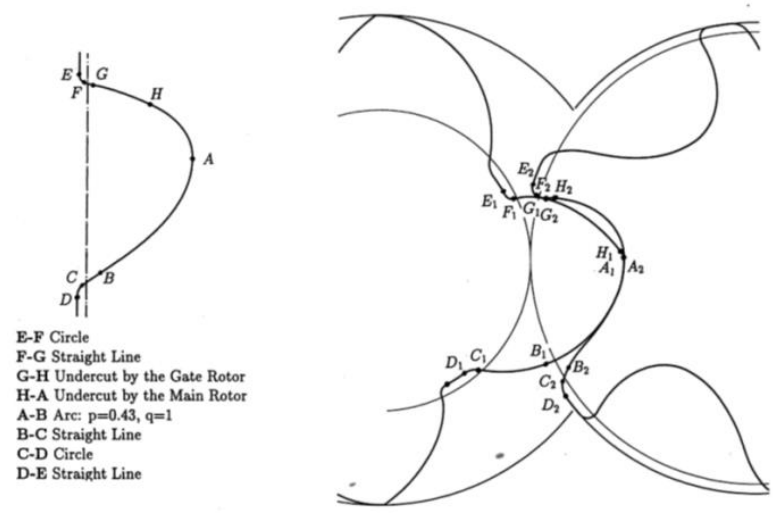

Figure 7: "N" profile

In Figure 8 the reference cross-section to compute the displacement and the preliminary design of the machine is presented. 


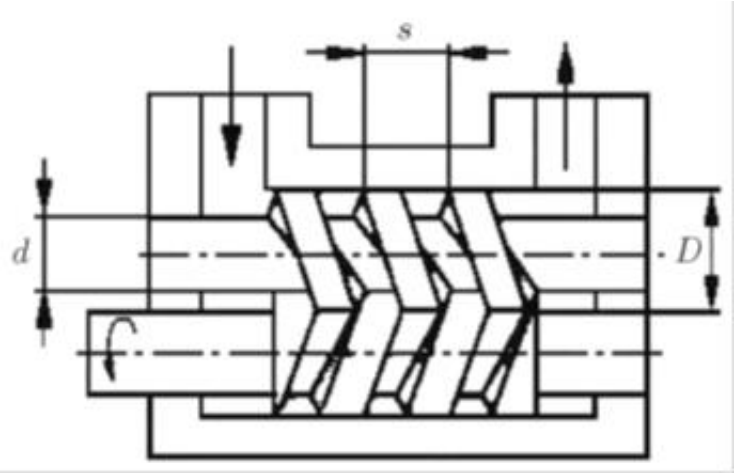

Figure 8: Reference cross-section

So, the displacement can be calculated as:

$\mathrm{V}=\mathrm{D}^{2} \cdot\left[\frac{\pi}{4} \cdot\left(1-\mathrm{d}^{2}\right)-\left(\frac{\alpha}{2}-\frac{\operatorname{sen} 2 \alpha}{2}\right)\right] \cdot \mathrm{s} \quad$ with $\cos \alpha=\frac{(\mathrm{D}+\mathrm{d})}{2 \mathrm{D}}$

The elaborated flow rate is function of the machine rotational speed " $\mathrm{n}$ " and the volumetric efficiency " $\eta_{\mathrm{v}}$ ":

$\mathrm{Q}=\eta_{\mathrm{v}} \cdot \mathrm{D}^{2} \cdot\left[\frac{\pi}{4} \cdot\left(1-\mathrm{d}^{2}\right)-\left(\frac{\alpha}{2}-\frac{\operatorname{sen} 2 \alpha}{2}\right)\right] \cdot \mathrm{s} \cdot \mathrm{n}$

Table 8: Design parameters for the Screw expander

\begin{tabular}{cccc}
\hline Parameter & Value & Parameter & Value \\
\hline $\boldsymbol{Q}_{\boldsymbol{i n}}$ & $0.0114 \mathrm{~m} 3 / \mathrm{s}$ & $\boldsymbol{Q}_{\text {out }}$ & $0.0616 \mathrm{~m} 3 / \mathrm{s}$ \\
\hline $\boldsymbol{h}$ & $37524.32 \mathrm{~J} / \mathrm{kg}$ & $\boldsymbol{\Delta}$ & $820 \mathrm{kPa}$
\end{tabular}

Once the design parameters are known (Table 8), with a nominal speed $\mathrm{n}=3000 \mathrm{rpm}$, the resulting displacement is: $\mathrm{V}=\mathrm{Q}_{\text {out }} / \mathrm{n}=1.23 \mathrm{l} / \mathrm{rev}$.

Moreover, the non-dimensional parameters shown in Table 9 have been set in similitude with existing screw machines.

Table 9: Aspect ratios of the Screw expander

\begin{tabular}{ccc}
\hline Parameter & Value \\
\hline $\boldsymbol{D}$ & 1.3 \\
$\overline{\boldsymbol{d}}$ & 1 \\
$\frac{\boldsymbol{d}}{\boldsymbol{s}}$ & $4+6$ \\
$\boldsymbol{N}_{\text {teeth }}$ & \\
\hline
\end{tabular}

Equation (14) evaluates the design parameters expressed in Table 10.

$\alpha=\operatorname{arcos}\left(\frac{1+\frac{d}{D}}{2}\right)$

$\mathrm{D}=\sqrt[3]{\frac{\mathrm{V}}{\left[\frac{\pi}{4}\left(1-\left(\frac{\mathrm{d}}{\mathrm{D}}\right)\right)^{2}-\left(\frac{\alpha}{2}-\frac{\sin 2 \alpha}{2}\right)\right] \frac{\mathrm{d} / \mathrm{D}}{\mathrm{d} / \mathrm{s}}}}$

The obtained tip speed is $\mathrm{v}_{\text {tip }}=23.31 \mathrm{~m} / \mathrm{s}$ which is consistent with "wet rotors" speed.

Table 10: Screw expander design results

\begin{tabular}{cc}
\hline Parameter & Value \\
\hline $\boldsymbol{D}$ & $148.3 \mathrm{~mm}$ \\
$\boldsymbol{d}$ & $114.1 \mathrm{~mm}$ \\
$\boldsymbol{S}$ & $114.1 \mathrm{~mm}$ \\
$\boldsymbol{n}$ & $3000 \mathrm{rpm}$ \\
\hline
\end{tabular}




\subsection{Losses and efficiency}

Several losses can be identified in:

- The rotors line of contact

- The vent formed between the rotors cusps and point of contact

- Losses on top of the rotors

- Losses on the inlet surface of the rotors

- Losses on the outlet surface of the rotors

During the expansion, leakage losses decrease the volumetric efficiency. Observing the operating conditions, the losses decrease, if the mixture ratio of the working fluid decreases. In fact, the formed liquid acts as sealant between the clearances, and as lubricating medium, for the moving parts a. This is why in our case we prefer a wet rotor with a liquid working fluid.

For the fluid dynamic losses, it should be considered the following statements. During the first part of admission, the pressure does not remain constant. There are concentrated losses, due to interaction between fluid vein and profiles (edges) of the various machine ducts. Fluid-dynamic studies have found that the concentrated loss coefficient is not dependent by the fluid admission speed; however, the loss is more important when the working fluid is in a moisture state. In fact for equal admission rate speed $\left(\mathrm{V}_{\text {in }}\right)$, the density increase, due to the presence liquid in the fluid, increases the losses, according to the law $\rho \mathrm{V}^{2}$ in. It can be noticed that the expansion is characterized by distributed losses, due to the friction between the working fluid and the chamber wall. The loss determination can be improving with computational fluid dynamics studies.

The empirical model proposed by V. Lemort [23] is a good candidate in evaluating the efficiency of the screw machine. The model has been implemented in Matlab, Python and other computational environments [24] and published in an open-source software named ORCmKit. For these reasons the expected machine efficiency is derived by similar existing expanders.

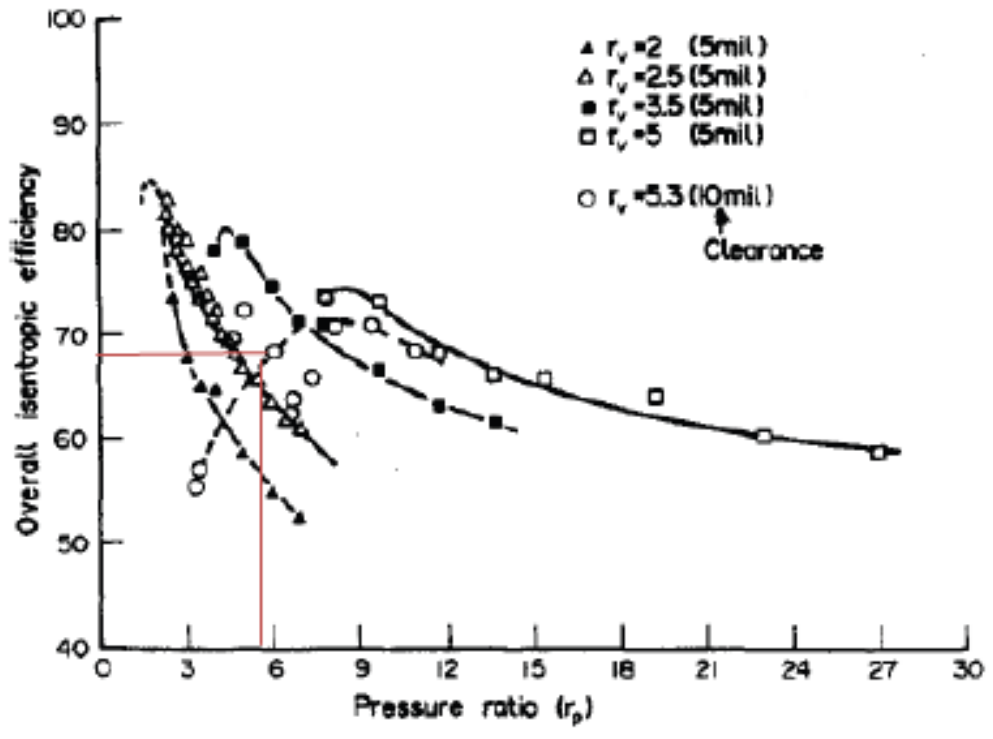

Figure 9: Map of measured performance, adapted from [13]

In Figure 9, a map of measured efficiency of different screw machines influenced by pressure and volume ratio is reported, adapted from [15].

Being in our case the pressure ratio $r_{p}=\frac{p_{0}}{p_{2}}=5.56$ and volume ratio $r_{v}=\frac{Q_{2}}{Q_{0}}=5.42$ the expected overall isentropic efficiency is $\eta_{\text {expected }}=0.68$.

\section{Rotary Vane Expanders}




\subsection{Rotary Vane Overview}

Rotary Vane Expanders and Compressors are common in the applications, where a good reliability at low cost and high volume ratios are needed. The simplest configuration consists in a circular rotor, rotating into a larger circular cavity. The centers of the rotor and the cavity present an eccentricity. Vanes are allowed to slide in and out the rotor creating chambers, which change in volume with an increasing crank angle. Because of their low technology, compactness and the possibility of high expansion ratios, Rotary Vane Expanders are often used in vacuum applications. The idea of Rotary Vane Expanders for ORC application is not new. However, only few recent published papers present experimental measurement and evaluations of Rotary Vane machines [25, 26]. The existing primary models difference be inherent in the vane thickness calculations. Many researchers have assumed a vane thickness equal to zero for calculating the chamber volume. According to recent work [27], a circular stator cylinder (common actual configuration) has been considered, and a vane thickness is taken into account. Thus, two arcs $\left(2 \pi-\theta_{\text {seal }}\right.$ and $\left.\theta_{\text {seal }}\right)$ can be identified. It should be noted that, if the sealing arc is symmetric, about the base line $(\theta=0)$, then the angle $\psi=180^{\circ}$ and $\operatorname{RS}(\theta)=180^{\circ}$. Neglecting the thickness of the vanes and assuming that the vanes are in continuous contact with the stator cylinder, the ideal volume for unit height of the expander cell, as a function of angular displacement, can be written as [26]:

$\mathrm{V}_{\text {cy_vanes }}(\theta)=\left[\mathrm{A}_{\text {cy_vanes }}(\theta)-\mathrm{A}_{\text {cy_vanes }}(\theta-\delta)\right]$

where $\mathrm{A}_{\text {cy_vanes }}(\theta)$ and $\mathrm{A}_{\text {cy_vanes }}(\theta-\delta)$ are the enclosed areas between the stator and rotor cylinders. The area functions can be evaluated using the equations and numerical procedure presented in $[28,29,30]$. The actual volume of the expander cells differs for the presence of the extended portions volume of the leading and trailing vanes, outside of the rotor slots. To evaluate the vanes kinematics and the actual volume of the expander cell, the vanes protrusions has to be computed. The vanes are assumed to be rigid. $R(\theta)$ is defined as the radius of the statorcylinder to the center of the rotor as a function of angular displacement. For a circular stator-cylinder this quantity is:

$R(\theta)=e \cdot \cos (\psi-\theta)+\sqrt{r_{R}^{2}+e^{2}-2 \cdot e \cdot r_{R} \cdot \cos \psi-e^{2} \cdot \operatorname{sen}^{2} \cdot(\psi-\theta)}$

where $\psi$ is defined as the angle between the arc and the rotor center.

The vane protrusion can be evaluated as:

$X(\theta)=R(\theta)-r_{R}$

\subsection{Design model}

The design of the Rotary Vane Expander has been performed using Matlab software. Once the geometrical parameters and the inlet and outlet volumetric flow are set, the program evaluates the maximum volume ratio, the angles, at which the inlet and outlet ports should be positioned, and plots the chamber volumes. The program returns a "warning text", if the desired flow does not match with the given geometrical parameters. Using this program, it is possible to generate $n$ potential geometries and choose the optimal geometry, in terms of compactness, aspect ratios and working machine expansion portion. As previously mentioned, the vane thickness is not considered. Recent studies pointed out how to a higher rotational speed corresponds a higher overall isentropic efficiency [26]. As previously done, the rotational speed is preliminary set to $n=4000 \mathrm{rpm}$. The chosen geometrical parameters for the volumetric expander are expressed in Table 11.

Table 11: Rotary Vane design parameters

\begin{tabular}{cccc}
\hline Parameter & Value & Parameter & Value \\
\hline $\boldsymbol{r}_{\boldsymbol{R}}$ & $100 \mathrm{~mm}$ & $\boldsymbol{e}$ & $30 \mathrm{~mm}$ \\
$\boldsymbol{n}_{\text {vanes }}$ & 8 & $\boldsymbol{h}$ & $260 \mathrm{~mm}$ \\
$\boldsymbol{Q}_{\boldsymbol{i n}}$ & $0.0114 \mathrm{~m} 3 / \mathrm{s}$ & $\boldsymbol{Q}_{\text {out }}$ & $0.0616 \mathrm{~m} 3 / \mathrm{s}$ \\
$\boldsymbol{\psi}$ & $160^{\circ}$ & $\boldsymbol{n}$ & $4000 \mathrm{rpm}$ \\
\hline
\end{tabular}


The desired chamber volume at inlet and outlet are evaluated, the function $R(\theta)$ (equation 20) is considered, and if the maximum vane protrusion exceeds a maximum value, set to $4 / 5$ of rotor radius, an error message is displayed. Then, for each chamber, the volume is evaluated at a fixed rotor position. For the $i^{\text {th }}$ chamber:

$\mathrm{V}(\mathrm{i})=\mathrm{h} \int_{\mathrm{i} \delta}^{(\mathrm{i}+1) \delta}\left(\mathrm{R}(\theta)-\mathrm{r}_{\mathrm{R}}\right) \mathrm{d} \theta$

If the maximum value of the volume is lower than the desired outlet volume, another message is displayed. Lastly, the value of theta angle, for which the $i^{\text {th }}$ chamber volume coincides with the inlet desired volume and with the desired outlet volume, is used as the inlet port angle and outlet port angle.

$\theta_{\text {in }} \cong 15^{\circ} ; \theta_{\text {out }} \cong 122^{\circ}$

A CAD sketch of the Rotary Vane expander is reported in Figure 10.
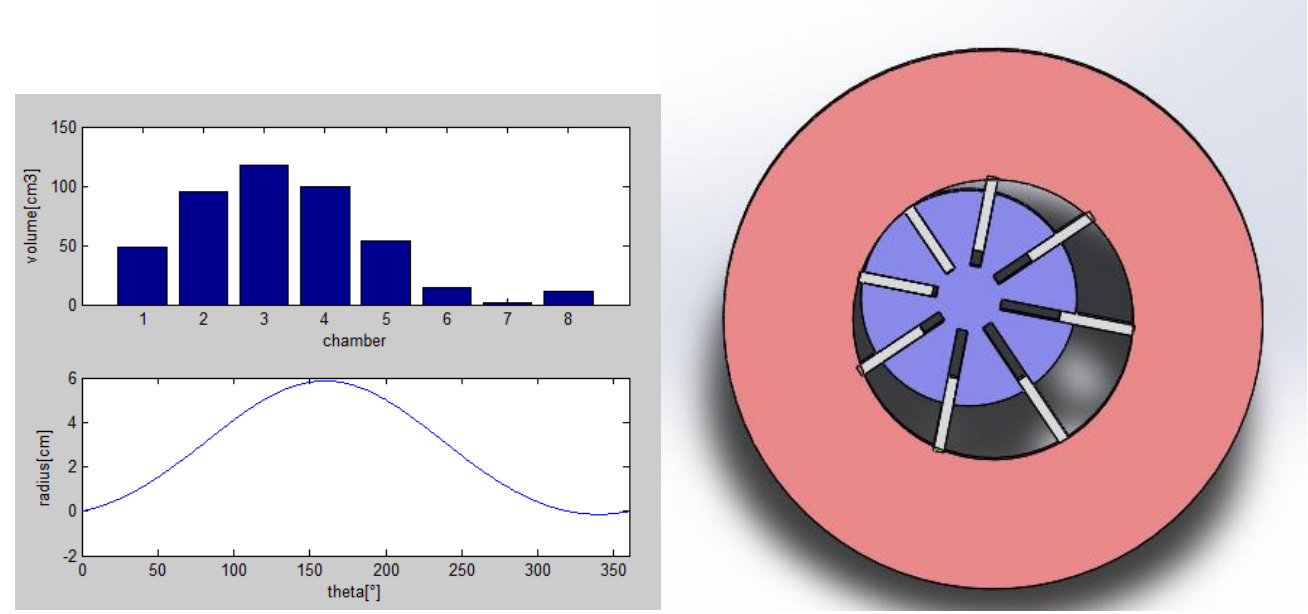

Figure 10: Rotary Vane sketch

\subsection{Losses and Efficiency}

In a Rotary Vane expander machine, losses could be divided into three categories:

1. Friction losses

2. Leakage losses

3. Thermal losses

Friction losses are related to the contact between the vanes and the rotor, the stator, and the rotor end plates. Those losses cannot be ignored, because the contact between the moving plate, sliding in and out the rotor, and in contact with the eccentric stator are the fundamental part of the machine. To deal with this problem, the moving plates are often made by low-friction material, such as graphite. Moreover, working with an organic fluid, with good lubrication properties, could lead to a "dry" rotor runner machine, with no oil need, even if this solution decreases substantially the expander operating life. As in screw expanders, in rotary vane expanders, the presence of liquid into the evolving chambers has proven to be an advantage. For this reason, a direct injection of working fluid, in liquid form, is expected. Leakage losses occurs between the chambers. As in [30] the leakage flow can be considered quasi-steady and laminar due to the small clearances in the vane expander. The fluid has been considered as an incompressible fluid, so that for the leakage flow along each leakage path can be assumed equal to:

$\dot{\mathrm{m}}_{\text {leakage }}=\frac{\rho}{\mu} \cdot \frac{2 \cdot\left(\mathrm{p}_{2}-\mathrm{p}_{1}\right) \cdot \mathrm{b}^{3} \cdot \mathrm{w}}{3 \cdot \Delta \mathrm{x}}$

Where:

$\Delta \mathrm{x} \quad$ length of the leakage paths as the line distance from the source to the sink 
width of the leakage paths determined by apportioning the total width of a leakage path at the single source over the total number of sinks the source leaked to along the leakage path

The heat transfer between the working fluid and the stator, as well as between the working fluid and the end plates, has to be calculated. It is need to evaluate the effect of heat transfer on the expander performance. The models can be one-dimensional or three-dimensional, totally empirical or semi-empirical. Since the purpose of this work is just to propose a "preliminary design procedure" of the possible expanders, previous works dealing with similar expanders were considered. In [26] a map of the measured volumetric efficiency of a purpose-made vane expander for ORC of similar characteristics is reported, showing the dependence on the pressure ratio and the rotational speed. So, a volumetric efficiency of $\eta_{\text {vol-vane }}=0.71$ and a lower overall isentropic efficiency should be expected. In fact, considering Figure 11, even if the expander is not tested for $\mathrm{r}_{\mathrm{p}}=5.56$, the general trend suggests an overall isentropic efficiency lower than 0.45 .

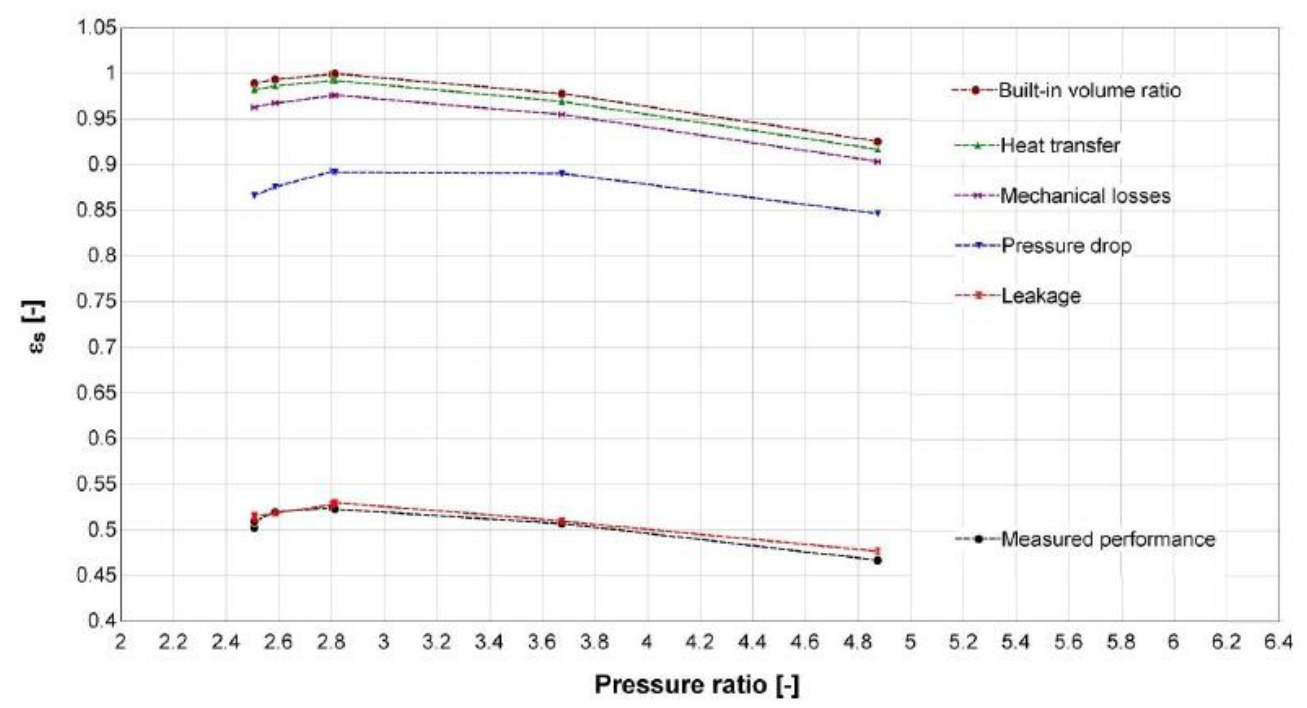

Figure 11: Map of measured performance, adapted from [24]

\section{Scroll Expanders}

\subsection{Scroll Expanders Overview}

The scroll machine is a good candidate to be used as expander, in small-scale ORC systems, for its compactness, simplicity of operation and reliability. Although older scrolls had an intrinsic small volume ratio (typically 3), the development of scroll expanders for larger volume ratios promotes the viability of this machine for ORC power generation, and nowadays, several investigations of scroll expander models and validation are described in literature. A scroll expander consists of two identical intermeshing spiral elements, placed in a chamber, with a difference phase of $180^{\circ}$. While one of the spiral is rigidly coupled to the stator, the other one orbits within it. Thanks to the movement of the inner scroll, the outer periphery forms a line of contact with the fixed scroll, forming a crescent shaped pocket. The working fluid at high pressure, entering through a port in the scroll center, generates forces on the scroll vanes, generating a torque, that produces the orbiting movement transferring the fluid to two adjacent vanes and forms symmetrical pockets.

The number of symmetric pockets formed, the volume ratio and the form of the pockets depends only on the scroll geometry. To define completely the scroll geometry, it has to specify:

1. orbiting angle

2. radius of the basic circle of the scroll

3. height of scroll vanes

4. initial angle of the inner involute

5. initial angle of the outer involute

6. ending angle of the inner involute 
7. ending angle of the outer involute

The orbiting angle is defined as the number of revolutions that the orbiting scroll must perform for completing a whole expansion cycle. The built-in volume ratio is the ratio between the volume of the expansion chamber at the end of the expansion and the volume of the intake chamber. The built-in volume ratio directly influences the capacity, operation and applicability of a scroll machine. Several investigations on the scroll, related to its geometries, are available in literature, even with varying scroll-wall thickness [33]. The most common shape of the scrolls is a circle involute. Every wrap is defined by two involutes, which develop from the same basic circumference, spaced by a constant distance (the wrap thickness). The inner portion is usually defined by the cutter, used to machine the scroll. In these figures, $\phi$ represents the generic involute angle, which defines the coordinates of each point of the inner and the outer profiles $\left(\left(\mathrm{x}_{\mathrm{in}}, \mathrm{y}_{\mathrm{in}}\right)\right.$ and $\left(\mathrm{x}_{\text {out }}, \mathrm{y}_{\text {out }}\right)$ respectively, $\alpha_{\text {in }}$ and $\alpha_{\text {out }}$ are the starting position angles of the inner and the outer involutes, $r_{b}$ is the radius of the basic circumference, $r_{c}$ is the radius of the circular arc forming the inner portion of the scrolls and, $\alpha_{\text {in_s }}$ and $\alpha_{\text {out_s }}$ are the initial angles of the inner and the outer spirals respectively. This accurate definition of geometry allows to evaluate the volume of all the machine chambers, at every orbiting angle, as the product of the scroll height and the area enclosed by the scrolls, between two consecutive angles of wrap contact. These equations are derived and fully described in Chen and Halm $[34,35]$. The suction volume, as a function of the shaft angle $\theta$, is expressed by:

$$
\mathrm{V}_{\mathrm{s}}(\theta)=\frac{1}{2} \mathrm{~h}_{\mathrm{s}} \mathrm{r}_{\mathrm{b}} \mathrm{r}_{0}\left[2 \varphi_{\mathrm{e}} \theta-\theta^{2}-\theta\left(\alpha_{\mathrm{i}}+\alpha_{0}+\pi\right)+2 \cdot(1-\cos \theta)-2 \cdot\left(\phi_{\mathrm{e}}-\pi\right) \operatorname{sen} \theta-\frac{\alpha_{\mathrm{i}}+\alpha_{0}}{2} \operatorname{sen}(2 \theta)\right]
$$

Where:

$\mathrm{h}_{\mathrm{s}} \quad$ height of the chambers

$\mathrm{r}_{\mathrm{o}} \quad$ radius of the orbiting circular path

$\phi_{e} \quad$ the ending angle of the involutes

Scroll expanders have numerous advantages, namely:

1. More efficient over their entire operating range

2. Operate at lower sound and vibration levels than traditional machines

3. Fewer moving parts

4. Ability to start under any system load, without assistance during starting

5. Easy to service and maintain due to their compact size, light weight, and simple design

6. No complex internal suction and discharge valves

7. Quieter operation and higher reliability due to few moving parts

8. Since high pressure fluid exerts pressure in all directions (tangentially, radial and axially) the requirement for axial bearing is omitted.

\subsection{Design model}

Design of the scroll expander has been implemented in Matlab software. Set the radius of the basic spirals circumference, the inlet volumetric flow rate and the desired expansion ratio, the program generates the machine geometry. The program does take into account the wall thickness, which is set to $0.5 \mathrm{~cm}$. The computed expansion ratio, if the wall thickness is considered, is higher than the computed one, without considering it. The medium profile starting angle is set to $\pi / 5$ in similitude with commercial scroll machines. Then, several profiles with different ending angle are generated, to achieve the desired volumetric expansion ratio in a dichotomy process.

Defining $\tau$ the orbiting angle of the moving scroll, the value of $\tau$, for which the charging process ends and the maximum of expansion occurs, are evaluated. Then, in these positions, the profiles contact points are calculated, to determine the pockets area within the scrolls. The ratio between these areas is the built-in volume ratio of the considered scroll machine.

The charging progress ends when the medium line between the inner and the outer spirals of the two scrolls are tangent. This occurs for a value of $\tau=\pi$. In this configuration, the contact points of the external fixed scroll and the internal moving scroll are evaluated. The distance of these points is the major semiaxis of the inlet ellipsoid. The minor semiaxis is evaluated as the distance between the center of the major semiaxis and the interception 
between a line, perpendicular to the major semiaxis, and the inner moving scroll. Finally the inlet area is evaluated as the area of the ellipsoid, deducted by the footprint area of the walls.

Similarly, the maximum expansion is obtained when the last contact point of the two scrolls coincides with the end point of one scrolls. Experimentally, even if the equation is not demonstrated, we have found that the maximum expansion is achieved at:

$\tau=\pi\left\{\bmod \left[\frac{\operatorname{int}\left(\frac{\max }{\pi}\right)}{2}\right]+\frac{\max }{\pi}-\operatorname{int}\left(\frac{\max }{\pi}\right)\right\}+\frac{\pi}{2}$

The outlet area is evaluated as previously mentioned and the resulting profiles are reported in Figure 12, while displayed profiles geometry is reported in Table 12.

Table 12: Scroll expander design results

\begin{tabular}{cccc}
\hline Parameter & Value & Parameter & Value \\
\hline $\boldsymbol{A}_{\boldsymbol{i n}}$ & $22.3410^{-3} 1 / \mathrm{rev}$ & $\boldsymbol{A}_{\text {out }}$ & $121.1210^{-3} \mathrm{l} / \mathrm{rev}$ \\
$\boldsymbol{r}_{\boldsymbol{v}}$ & 5.42 & $\boldsymbol{h}$ & $101.7 \mathrm{~mm}$ \\
$\boldsymbol{D}_{\boldsymbol{m a x}}$ & $179.4 \mathrm{~mm}$ & $\boldsymbol{\phi}_{\text {end }}$ & $7.4 \pi$ \\
$\boldsymbol{n}$ & $3000 \mathrm{rpm}$ & & \\
\hline
\end{tabular}

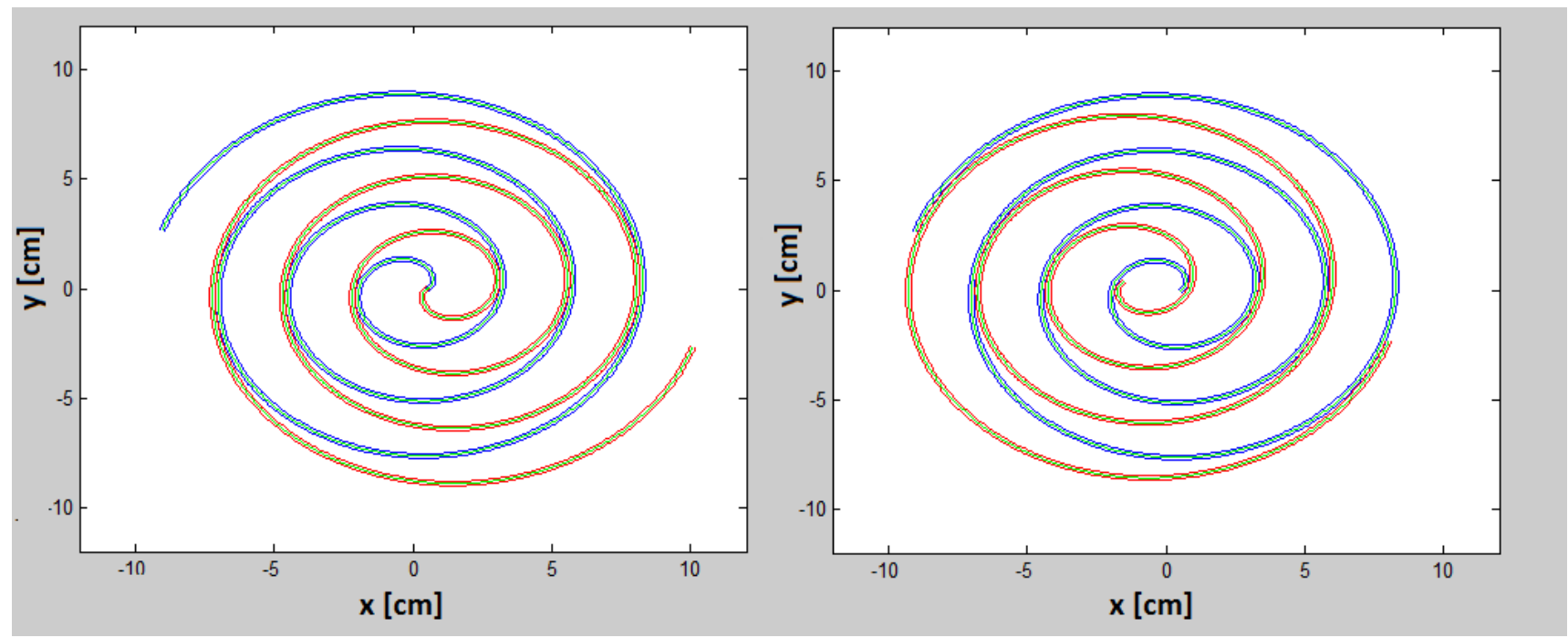

Starting expansion

Ending expansion

Figure 12: Scroll geometry

\subsection{Losses and Efficiency}

Scroll expanders show axial and radial compliances (which requires lubrication of both scrolls) or can be cinematically rigid. In the latter configuration there is no contact between both scrolls, and no lubrication is needed (so called "dry scrolls" or "oil-free"). Radial leakages are limited by using tip seals placed on the scroll itself. Cinematically, rigid expanders are generally open-drive; in that case, using a magnetic coupling could ensure the tightness of the machine. However, the typically moderate amount of working hours for oil-free scrolls $(<10000)$ makes its use unlikable for on-board applications. However expecting an oil lubricated scroll implies the need of an high efficiency oil separator. In fact, the oil, can even decompose if a contact with hot spots occurs. Alternatively, if a little amount of oil flows through the evaporator, causing carbon-like particulate, and damaging the other components.

Leakages are the main loss mechanism. Ideally, the two halves of a scroll remain perfectly in contact, during rotation. Actually, it cannot be practically obtained. Due to required tolerance, a narrow gap remains. Typically, the gap is approximately one micron. Once this gap reaches the values of eight microns, the machine becomes useless. There are two types of by-pass flow (in the form of leakage), that occur in a scroll expander: radial and 
axial flow. Radial leakage are present between consecutive sides of the vanes. The axial leakage occurs between the vane tip and the base plate of the opposite scroll. This is showed in Figure 13. The fluid leakage occurs from the higher pressure side to the lower pressure side, toward the discharge side, creating a by-pass flow, which decreases the generated power.

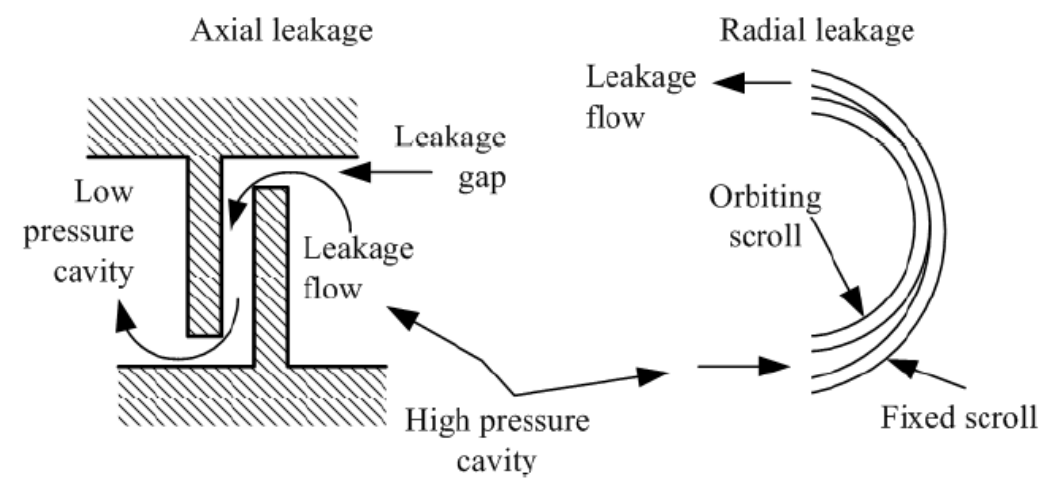

Figure 13: Axial and Radial Leakages

It is possible to consider such a losses in the energy analysis of a scroll expander, according to the nozzle leakage model proposed by Liansheng in 1998. Radial leakage can be expressed as:

$\frac{\mathrm{dm}_{\text {leak_in_axial }}}{\mathrm{d} \theta}=-\frac{\Phi_{\text {axial }} \rho_{\text {in }}(\theta) c_{\text {axial }} L_{\text {in_radial }}(\theta)}{\omega} \sqrt{\frac{2 \mathrm{k}}{\mathrm{k}-1} \mathrm{RT}_{\text {in }}(\theta)\left[1-\left(\frac{\mathrm{p}_{\text {in }+1}(\theta)}{\mathrm{p}_{\text {in }}(\theta)}\right)^{\frac{\mathrm{k}-1}{\mathrm{k}}}\right]}$

While axial leakages:

$\frac{\mathrm{dm}_{\text {leak_in_radial }}}{\mathrm{d} \theta}=-\frac{\Phi_{\text {radial }} \rho_{\text {in }}(\theta) \mathrm{c}_{\text {radial }} \cdot \mathrm{h}}{\omega} \sqrt{\frac{2 \mathrm{k}}{\mathrm{k}-1} \mathrm{RT}_{\mathrm{in}}(\theta)\left[1-\left(\frac{\mathrm{p}_{\text {in }+1}(\theta)}{\mathrm{p}_{\text {in }}(\theta)}\right)^{\frac{\mathrm{k}-1}{\mathrm{k}}}\right]}$

Where:

$\begin{array}{ll}\mathrm{r} & \text { inlet fluid density } \\ \mathrm{L} & \text { length of leakage clearance } \\ \phi & \text { flow coefficient } \\ \mathrm{c} & \text { average leakage clearance } \\ \theta & \text { angular displacement }\end{array}$

Solving equations (27), (28), it is possible to analytically obtain all the scroll operating parameters.

As previously defined, the available data, for obtaining the expected efficiency, have been considered. In [15] a chart reporting the scroll expander efficiency tested with fluid R245fa, varying the pressure ratio, is presented (Figure 14). 


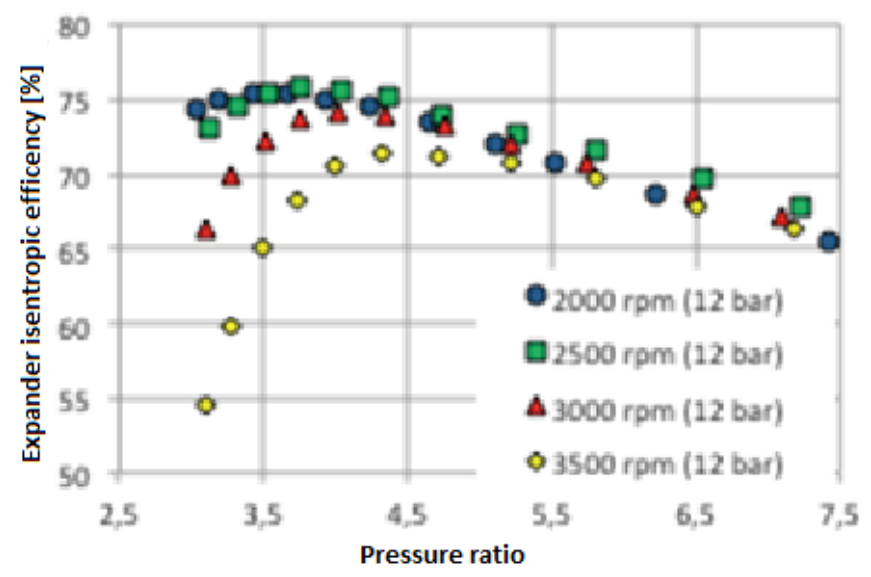

Figure 14: Map of measured performance, adapted from [13]

According to this work, an efficiency of $\eta_{\text {scroll }} \cong 0.7$ should be expected.

Similar results are achieved in [31] and [36] even if. the tests have been carried out using a different working fluids. Chart is reported in Figure 15.

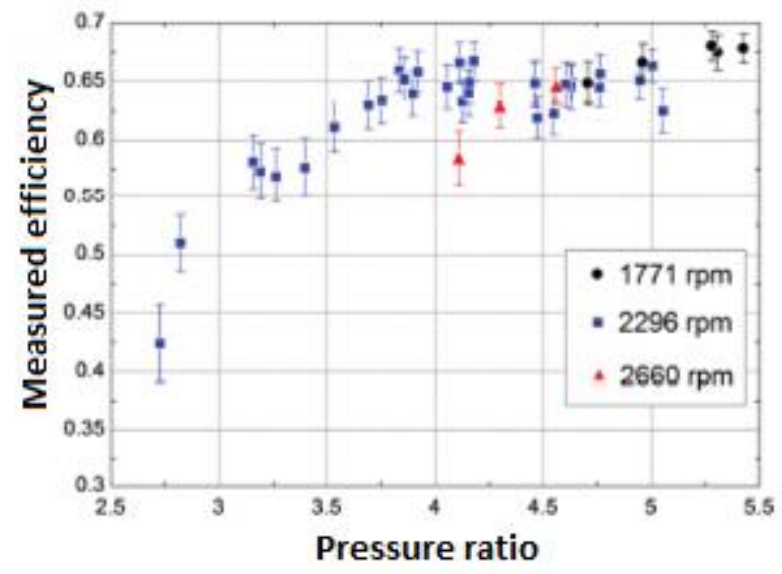

Figure 15: Map of measured performance adapted from [29]

\section{Choice}

The aim of this work is to suggest the final choice of the optimal expander. For this reason, it has been decided to realize a table (Table 13) of all the relevant issues to be dealt with, and give them a mark from 1 (least desirable) to 3 (most desirable) for each expander.

The considered parameters for the choice are the following:

-Efficiency: Overall isentropic efficiency. Even if, as previously mentioned, no volumetric expander could challenge an IFR in terms of efficiency, both scroll and screw expanders have shown interesting efficiencies.

-Machine Volume: Represents machine overall dimensions. Also in this case, the turbine shows the optimal characteristics. The screw expander has the greatest volume, while the scroll machine offers a good compromise between volume and efficiency.

-MTBF: Mean Time Between Failure. The scroll and the screw machine present few moving parts, which can either be in contact, if a good lubrication is expected, or built with a clearance. This arrangement decrease the machine efficiency, but guarantees the absence of contact, reducing damage. Moreover, the low rotational speed of the volumetric machines generates low stress on the bearings, increasing the maintenance stops and their reliability. 
-Lubrication: While the turbine does not present issues related to lubrication, the issues related to the screw motor can be relatively easily dealt by choosing an unsynchronized configuration. Moreover, the use of a working fluid with good lubrication proprieties contribute to figure out the problem. Both scroll and rotary vane expanders, to guarantee a good reliability and a longer life, should not be oil-free.

-EM Coupling: The simplicity of connection to an electric generator mostly depends on the rotational speed. For this parameter the turbine is the least favorable.

-PLE: Partial Load Efficiency. IFR turbines low flexibility makes their use undesirable in partial load applications. The volumetric expanders, instead, show a great flexibility and can operate smoothly under unsteady conditions. That is the main reason for choosing these machines in bottoming ORC systems. Finally, The screw motor has shown an excellent behavior under unsteady conditions.

-Power Density: While it is clear that no volumetric expander can challenge the micro turbine power density (often above $5 \mathrm{~kW} / \mathrm{kg}$ ), the scroll expander shows an interesting value, from 50 to $150 \mathrm{~W} / \mathrm{kg}$. Even if the screw machine presents a very high volume, its efficiency keeps the power density around $40 \mathrm{~kW} / \mathrm{kg}$. The Scroll expander has the lowest value (from 20 to $30 \mathrm{~kW} / \mathrm{kg}$ ), due to its low efficiency.

Table 13: Expander choice

\begin{tabular}{lcccc}
\hline & IFR & SCREW & ROTARY VANE & SCROLL \\
\hline Efficiency & 3 & 2 & 1 & 2 \\
Machine Volume & 3 & 1 & 1 & 2 \\
MTBF & 2 & 3 & 2 & 3 \\
Lubrication & 3 & 3 & 2 & 1 \\
EM Coupling & 1 & 3 & 3 & 3 \\
PLE & 1 & 3 & 2 & 3 \\
Power Density & 3 & 2 & 1 & 16 \\
TOTAL & 16 & 17 & 12 & \\
\hline
\end{tabular}

According to this procedure, the screw machine seems to be the optimal compromise for this purpose. However, depending on the application, the relative weight of each characteristic should be considered, thus making a general procedure of choice extremely challenging. Moreover, since ORC bottoming cycles for waste heat application are, in general, not commercial, each component should be designed and manufactured ad-hoc, requiring a highly investment, and a cost analysis should be carried out for each component design.Finally, Table 14 shows the advantages and the disadvantages of each considered expander.

Table 14: Expander comparison

\begin{tabular}{|c|c|c|}
\hline Expander & Advantages & Disadvantages \\
\hline$I F R$ & $\begin{array}{l}\text { High specific power } \\
\text { High efficiency }\end{array}$ & $\begin{array}{l}\text { Efficiency drop under unsteady } \\
\text { conditions } \\
\text { High speed } \\
\text { High cost }\end{array}$ \\
\hline SCREW & $\begin{array}{l}\text { Low cost } \\
\text { Good lubrication } \\
\text { High partial load efficiency } \\
\text { Good efficiency }\end{array}$ & High Volume \\
\hline ROTARY VANE & $\begin{array}{l}\text { Low cost } \\
\text { Simple production }\end{array}$ & $\begin{array}{l}\text { Low efficiency } \\
\text { High Volume } \\
\text { Low power density }\end{array}$ \\
\hline SCROLL & $\begin{array}{l}\text { Good efficiency } \\
\text { Good lubrication } \\
\text { Good power density }\end{array}$ & $\begin{array}{l}\text { Lubrication } \\
\text { High Volume }\end{array}$ \\
\hline
\end{tabular}




\section{Conclusions}

In this work the feasibility of an on board ORC energy recovery system for bus application has been examined. To perform and propose a procedure for the expander choice, IFR turbine, Screw expander, Scroll expander and Rotary Vane expander have been preliminary designed with MATLAB software, via an iterative procedure, that support every fluid choice. The principal issues related to each machine in terms of lubrication, efficiency and reliability are discussed and compared. The final choice focused on the screw motor, for it is the optimal compromise in terms of efficiency, lubrication and reliability. Moreover today screw expanders show a much larger technical maturity than scroll and rotary vane expanders. However, it has been pointed out how the choice may vary, depending on the relative weight of every expander characteristic, on the whole energy recovery system for each target application.

\section{Funding Sources}

This research did not receive any specific grant from funding agencies in the public, commercial, or not-forprofit sectors.

\section{References}

[1] Communication from the Commission to the European Parliament and the Council: "Energy Efficiency and its contribution to energy security and the 2030 Framework for climate and energy policy"-Brussels, 23.7.2014 $\mathrm{COM}(2014) 520$ final.

[2] Li G." Review of thermal energy storage technologies and experimental investigation of adsorption thermal energy storage for residential application", University of Maryland at College Park (Thesis)2013

[3] "Cold Thermal Energy Storage Materials and Applications toward Sustainability". Energy Solutions to Combat Global Warming. Volume 33 of the series Lecture Notes in Energy pp 67-117 Springer International Publishing, 2016

[4] Gang Li, Xuefei Zheng, "Thermal energy storage system integration forms for a sustainable future”, Renewable \& Sustainable Energy Reviews 2016, 62, 736-757

[5] Gang Li, "Energy and exergy performance assessments for latent heat thermal energy storage system”, Renewable \& Sustainable Energy Reviews 2015, 51, 926-954

[6] Gang Li, "Sensible heat thermal storage energy and exergy performance evaluations", Renewable \& Sustainable Energy Reviews 2016, 53, 897-923

[7] Gang Li, Yunho Hwang, Reinhard Radermacher, Ho-Hwan Chun, "Review of cold storage materials for subzero applications", Energy 2013,51, 1-17

[8] P. Colonna, E. Casati, C. Trapp, T. Mathijssen, J. Larjola, T. Turunrn-Saaresti, A.Usitalo, "Organic Rankine Cycle Power Systems: From the Concept to the Current technology, Applications, and Outlook to the Future", 2015- ASME digital collection.

[9] C.Soffientini, G.J.Zyhowski, M.W.Spatz, "HFC-245fa: An Overview of Proprieties and Applications", X" European Conference on Technological Innovations in Air Conditioning and Refrigeration Industry, Milan, 2003.

[10] CAMEL-Pro User Manual, rev4, 2008 <www.turbomachinery.it>.

[11] M.Falcetta, E.Sciubba, "A computational modular approach to the simulation of power plants"-ASMEAES Heat Recovery Syst CHP 1995;15(2).

[12] Gang Li, "Organic Rankine cycle performance evaluation and thermoeconomic assessment with various applications part I: energy and exergy performance evaluation"'- Renewable \& Sustainable Energy Reviews 53, 477-499, 2016.

[13] Gang Li, "Rankine cycle performance evaluation and thermoeconomic assessment with various applications part II: Economic assessment aspect"- Renewable \& Sustainable Energy Reviews 64, 490-505, 2016.

[14] R. Capata, C. Toro, "Feasibility analysis of a small-scale ORC energy recovery system for vehicular application" - Energy Conversion and Management, June 2014.

[15] V. Lemort, L. Guillaume, A. Legros, S. Declaye, S. Quoilin, “A comparison of piston, screw and scroll expanders for small-scale Rankine Cycle Systems" - Thermodynamics Laboratory, University of Liege, Campus du Sart Tilman, B49, 4000, Liege, Belgium. 
[16] H.E. Rohlik, "Analytical Determination of Radial Inflow Turbine Design Geometry for Maximum Efficiency" - NASA Technical Note1968.

[17] R. Capata, G. Hernandez "Preliminary Design and Simulation of a turbo expanders for small rated power organic Rankine cycle (ORC)” - Energies 7 (11), 7067-7093, 2014.

[18] O.E. Balje, “Turbomachines: A Guide to Design, Selection and Theory"- 1981.

[19] S.L. Dixon, C.A. Hall, “Fluid Mechanics and Thermodynamics of Turbomachinery”- Elsevier Inc. $6^{\text {th }}$ Edition.

[20] Prof.Dr.-Ing. Andreas Brümmer, "Energy efficiency - waste heat utilization with screw expanders" Pumps, Compressors and Process Components 2012 pp 120-126.

[21] Dipl.-Ing. Jan Hütker, Univ.Prof.Dr.-Ing. Andreas Brümmer, "A comparative examination of steam powered screw motors for specific installation conditions" TU-Dortmund, Chair of Fluidics.

[22] N.Stosic, I. Smith, K. Kovacevic, A and Aldis, "The design of a twin-screw compressor based on a new rotor profile” C. A. - Journal of Engineering Design, vol 8, n.4, pp 389-399, 1997.

[23] D. Ziviani, A. Desideri, V. Lemort, M. De Paepe, M. Van Den Broek, "Low-order models of a single screw expander for organic Rankine cycle application” - IOP Conference Series Materials Science and Engineering . August 2015.

[24] R. Dickes, D. Ziviani, M. De Paepe, M. Van Den Broek, S. Quoilin, V. Lemort, "ORCmKit: an open-source library for organic Rankine cycle modeling analysis"- Proceedings of ECOS 2016.

[25] G. Montenegro, A. Della Torre, M. Fiocco, A. Onorati, C. Benatzky, G. Schlager, "Evaluating the Performance of a Rotary Vane Expander for Small Scale Organic Rankine Cycles using CFD tools" - $68^{\text {th }}$ Conference of the Italian Thermal Machines Engineering Association, ATI2013.

[26] V. Vodicka, L. Guillaume, J. Mascuch, V. Lemort, "Testing and Modelling a Vane Expander used in an ORC working with Hexamethyldiloxane $(M M)$ " $-3^{\text {rd }}$ International Seminar on ORC Power Systems, October 12-14, 2015, Brussels, Belgium.

[27] A. M. Mahmoud, "Analytical and Experimental investigation of Rotary Vane two phase Expanders in vapor compression refrigeration systems"- PhD Thesis University of Florida 2008.

[28] O. Badr, P.W. O'Callaghan, and S.D. Probert, "Multi-Vane Expanders: Geometry and Kinematics" Applied Energy (19), pp. 159-182, 1985.

[29] O. Badr, P.W. O'Callaghan, and S.D. Probert, “Multi-Vane Expander Performance: Breathing Characteristics" - Applied Energy (19), pp. 241-271, 1985.

[30] O. Badr, P.W. O'Callaghan, and S.D. Probert, “Multi-vane Expanders: Internal-Leakage Losses - Applied Energy (20), pp. 1-46, 1985.

[31] V. Lemort, S. Quoilin, "Designing scroll expanders for use in heat recovery Rankine cycles" - IMechE, 2009.

[32] V. Lemort, I.V. Teodorese, J. Lebrun, "Experimental Study of the Integration of a Scroll Expander Into a Heat Recovery Rankine Cycle" - International Compressor Engineering Conference at Purdue, July 17-20, 2006.

[33] M.S. Orosz, A. V. Mueller, B. J. Dechesne, H. F. Hemond, “Geometric Design of Scroll Expanders Optimized for Small Organic Rankine Cycles" - Journal of Engineering for Gas Turbines and Power, APRIL 2013, Vol. 135, ASME.

[34] Y. Chen, N. P. Halm, E. A. Groll, and J. E. Braun, "Mathematical modeling of scroll compressors part I: compressor process modeling"- International Journal of Refrigeration, 25:731-750, 2002.

[35] Y. Chen, N. P. Halm, J. E. Braun, and E. A. Groll, "Mathematical modeling of scroll compressors - part II: overall scroll compressor modeling"- International Journal of Refrigeration, 25:751-764, 2002.

[36] S. Quoilin, V. Lemort, J. Lebrun, "Experimental study and modeling of an Organic Rankine Cycle using scroll expanders”- Applied Energy, Volume 87, issue 4, 1260-1268, April 2010. 